\title{
Swiss University Students' Risk Perception and General Anxiety during the COVID-19 Pandemic
}

\author{
Julia Dratva ${ }^{1,2, * \mathbb{C}}$, Annina Zysset ${ }^{1}$, Nadine Schlatter ${ }^{1}$, Agnes von $\mathrm{Wyl}^{3}{ }^{3}$, Marion Huber ${ }^{1}$ (D) \\ and Thomas Volken ${ }^{1}$ D \\ 1 Department of Health, Institute of Health Sciences, Zurich University of Applied Sciences Winterthur, \\ 8400 Winterthur, Switzerland; annina.zysset@zhaw.ch (A.Z.); nadine.wanner@gmail.com (N.S.); \\ marion.huber@zhaw.ch (M.H.); thomas.volken@zhaw.ch (T.V.) \\ 2 Medical Faculty, University of Basel, 4001 Basel, Switzerland \\ 3 Department of Psychology, Zurich University of Applied Sciences Winterthur, 8400 Winterthur, Switzerland; \\ vonw@zhaw.ch \\ * Correspondence: julia.dratva@zhaw.ch
}

Received: 6 September 2020; Accepted: 6 October 2020; Published: 13 October 2020

check for updates

\begin{abstract}
University students were confronted with abrupt changes to their daily lives by the COVID-19 lock-down. We investigated Generalized Anxiety Disorder Scale-7 (GAD-7) and anxiety levels, and the association between perceived impact on well-being, studies, and daily lives and anxiety levels, adjusted for gender, age, social class and affiliation. Early in the lock-down all students of the Zurich University of Applied Sciences $(N=12,429)$ were invited to a voluntary longitudinal health survey. Participation rate was 20\% $(n=2437)$ : $70 \%$ females, median age 25 yrs. (IQR 23-28). A total of $10 \%$ reported a deterioration of well-being compared to pre-Corona. LCA yielded three classes varying in perceived COVID-19 impact: 1 (low, $n=675), 2$ (moderate, $n=1098$ ), and 3 (strong, $n=656$ ). Adjusted proportion of moderate to severe anxiety by class were $45 \%$ (95\% CI: 28.0-62.0), 15.5\% (95\% CI: 13.1-17.9), and 5.1\% (95\% CI: 4.7-5.6), respectively. Multivariate regression analyses yielded an OR for moderate to severe anxiety of 3.88 (95\% CI: 2.5-6.0, class 2) and 22.43 (95\% CI: 14.5-34.6, class 3) compared to class-1. The investigated association implies that containment measures have a selective effect on anxiety in students. The diversity of students' perception and associated anxiety should be monitored and considered in future response to pandemics.
\end{abstract}

Keywords: anxiety; COVID-19; GAD-7; latent class analyses; university students; young adults

\section{Introduction}

Public health measures implemented in reaction to COVID-19 had an enormous impact on daily lives of all citizens. Similar to other countries, and in view of dramatic developments in Italy [1], a neighboring country, Switzerland introduced containment policies including closure of schools and universities (17 March 2020), restriction of gatherings to maximum of five persons together with a general recommendation to stay at home whenever possible (21 March 2020), next to preparing the health services for a high number of infected in need of intensive medical care. University students are not considered a risk group for COVID-19; however, the threatening news can potentially cause stress, fear [2], concern for family members, and drastic changes in daily routines, social contacts, and finances [3]. The United Nations Educational, Scientific and Cultural Organization (UNESCO) estimates that $60 \%$ of all students globally are affected by school closures [4], and numerous experts anticipate an adverse impact on mental health due to the pandemic and its containment measures [5-9]. Mental health problems and disorders are a serious public health issue in students with a fifth of 
students affected worldwide $[10,11]$. General population studies find current prevalence rates of $1.5 \%$ to $3.0 \%$, lifetime rates of 4.0-7.0\% [12-14], and substantial burden and impairment [15].

Despite recent large-scale epidemics and pandemics, such as SARS, H1N1 avian flu or Ebola, very little research has been performed on the effect of these acute and personally uncontrollable stressors in students' mental health or the role of universities' in alleviating the stress [16,17]. A recent rapid review on behaviors and mental health outcomes in pandemics and general populations indicates that, among the outcomes investigated in the past, anxiety and worry can have a significant impact on the daily life and work $[18,19]$. The prevalence and severity of anxiety and worry, feeling of panic, depression and emotional disturbance, was initially high, decreasing over time [19].

First evidence on adverse impact by COVID-19 on students' mental health comes from China. Cao et al. studied students at Changzhi medical college and Zhou et al. researched a Chinese adolescent population $[20,21]$. A study from Saudi Arabia investigated medical students and found anxiety to be associated with increased hygiene and social avoidance behavior [22]. A longitudinal study in Switzerland investigated emotional distress and concluded an increase and association with prior resilience and coping strategies [23].

The "HEalth in Students study during the Corona pandemic" (HES-C) aims to (1) evaluate the mental situation of students during the epidemic, (2) investigate changes in health behavior and associated factors, as well as (3) study student's perception of the pandemic and related measures and their impact on students' lives. This paper investigates the impact on student's daily lives and how this relates to their anxiety levels.

\section{Materials and Methods}

Students from all faculties of the Zurich University of Applied Sciences (ZHAW) $(N=12,431)$, a university of applied sciences in the German speaking part of Switzerland, received a non-personalized email inviting them to participate in the study, providing study information, and a link to the survey and the study homepage. The study was approved by both the local cantonal ethics committee (BASEC-Nr. Req-2020-00326) and the ZHAW data protection officer. The baseline survey ran from 3 to 14 April 2020. The net participation rate was $20 \%$. Participation rates by department and respective to department student number differed: Applied Linguistics 23\%, Applied Psychology 30\%, Architecture, Design and Civil Engineering 13\%, Health Profession 35\%, Life Science and Facility Management 21\%, School of Engineering 17\%, School of management and Law 11\%, and Social Work 31\%.

The questionnaire contained internationally accepted standardized instruments and questions to assess subjective wellbeing, health status, mental health and health behavior, as well as a set of questions on COVID-19 pandemic, partly specifically developed for this target group and their context and partly adapted from a Swiss survey addressing the general population [24] (see online supplement Table S1: Overview of HES-C topics and instruments). The questionnaire was developed by the authors representing researchers, lecturers and students. Five students of different faculties piloted the questionnaire reporting any technical and content issues. Our target outcome, anxiety, was measured with the General Anxiety Disorder-Scale-7 (GAD-7; Spitzer, Kroenke, Williams and Löwe, 2006). The GAD-7 is a self-assessment questionnaire that measures the level of perceived anxiety in the last two weeks. The questionnaire is comprised of 7 items to be rated on a 4-point Likert scale (from "not at all" to "nearly every day"). The resulting sum score ranges from 0 to 21 , with lower values indicating lower level of anxiety, and is categorized into four severity levels of anxiety: minimal (0-4), mild (5-9), moderate (10-14) and severe (15-21).

Students were asked about the effects of COVID-19 pandemic and the public health measures on their subjective wellbeing and their students' and everyday life. They answered to questions (Q1) and (Q2) "How are you doing at the moment/were you doing before the pandemic?" on a 5-point Likert scale $(1=$ very poor to $5=$ very good $)$, and were asked to agree or not agree to provided statements on a 5-point Likert scale ( 1 = strongly disagree, $5=$ strongly agree, "not relevant"). The statements regarding students life were: (Q3) My timetable and thus my daily structure has changed a lot; (Q4) My weekly 
workload has reduced; (Q5) My weekly workload has increased; (Q6) I miss the social contacts with my fellow students; (Q7) The lecturers are available as contact persons for the students; (Q8) The higher proportion of self-study allows me more freedom; (Q9) The higher proportion of self-study is a huge challenge for me; (Q10) I am well informed about the consequences of the ZHAW's decisions concerning my semester examinations; (Q11) I am worried about my semester degree; (Q12) I can carry out my planned internships (during my studies or during the summer holidays). Statements on everyday life were taken from a survey by the national broadcasting service [24]: (Q13) I experience more tense and conflict; (Q14) I am lonely; (Q15) I experience a stronger neighborhood; (Q16). I am bored; (Q17) I feel locked up; (Q18) I enjoy time with my family/partner; (Q19) Childcare is challenging; (Q20) No specific impact.

We also assessed the concerns students had about themselves or their family (parents, siblings, grandparents, own child/child of partner, other relative). They could answer the question "Are you concerned about your own health in the context of the pandemic?" with either "I have no concerns" $(=1)$, " ... some concerns" (=2) and " $\ldots$ big concerns" (=3). For family members financial concerns were addressed in the same manner, omitting the question on "child".

Sociodemographic variables collected were age (year of birth), gender, nationality, university departmental affiliation, subject of study, pursued degree (BSc., MSc.), part-time vs. full-time study and living situation, currently and before the pandemic. Subjective parental social status at student age 16 years. (McArthur Scale, [25]) and place of birth was assessed.

\section{Statistical Analyses}

In order to capture variations in students' subjective wellbeing and perceptions of everyday life during the COVID-19 lockdown, we employed a latent class analysis (LCA) of the multinomial family with logit link. Classes were inferred from all 20 available indicators on subjective wellbeing and students' perceptions of everyday life. Indicators leading to boundary parameter estimates, i.e., probabilities very close to zero or one (logit $+/-15.0)$, were dropped from the pool of indicators as they cause numerical problems in estimation algorithms [26], may indicate identification problems or convergence to a local likelihood maximum [27]. In the final LCA, the following indicators were included: (Q1), (Q8), (Q9), (Q11), (Q13), (Q14), (Q17), (Q18), and (Q20). A total of 5 LCA models involving one to five latent classes were estimated using the maximum likelihood method. Based on the Bayesian information criteria (BIC), the model with three latent classes was selected.

In a first step, ordinary least-square (OLS) regression with robust standard errors were used to estimate unadjusted and adjusted models for anxiety. All models included the LCA derived classes. Moreover, adjusted models included gender, age (centered at the mean value), parental social status (centered at the mean value), foreign nationality (reference: Swiss nationality), and university department affiliation (reference: department of health professions).

In a second step, we used binary logistic regressions with robust standard errors to estimate unadjusted and adjusted models for anxiety at pre-defined, clinically relevant cut-off points for severe level of anxiety (GAD-7 $\geq 15$ and moderate to severe level of anxiety (GAD-7 $\geq 10$ ) [28].

We used Stata Version 15.1 (StataCorp, College Station, TX, USA) for all statistical analyses. Statistical significance was established at $p<0.05$.

\section{Results}

The study sample contains students from all faculties $(N=2429)$, students from the school of health professions and social work were slightly overrepresented (Table 1). A total of $70 \%$ were female students and the median age was 25 years (IQR 23-28); 12\% reported feeling "poor" to "very poor" (current wellbeing); $10 \%$ of the students $(n=196)$, who had felt "very good", "good" or "fair" before the pandemic now reported feeling "very poor" or "poor", while among those 57 students who had felt poorly before, about two-thirds indicated an improved wellbeing ("fair"-"very good", $n=39$ ). Students who answered the question on health concerns regarding COVID-19 ( $N=2080)$ voiced little 
concern for themselves (some concern $41.0 \%$, big concern $2.7 \%$ ), while major concern for relatives was frequent (some concern: parent (p) 53.1\%, grandparents (gp) 49.6\%; major concern: p 23.8\%, gp 41.1\%).

Table 1. Participants' characteristics by latent classes.

\begin{tabular}{|c|c|c|c|c|}
\hline \multirow[t]{2}{*}{ Characteristics } & $\begin{array}{c}\text { Total } \\
(N=2429)\end{array}$ & $\begin{array}{c}\text { Latent Class } 1^{1} \\
(n=675)\end{array}$ & $\begin{array}{c}{\text { Class } 2^{1}}_{(n=1098)} \\
\end{array}$ & $\begin{array}{l}{\text { Class } 3^{1}}_{(n=656)} \\
\end{array}$ \\
\hline & $\mathrm{M}(\mathrm{SD}) / \%$ & $\mathrm{M}(\mathrm{SD}) / \%$ & $\mathrm{M}(\mathrm{SD}) / \%$ & $\mathrm{M}(\mathrm{SD}) / \%$ \\
\hline Age (years) ** & $26.4(5.6)$ & $26.9(5.9)$ & $26.0(5.2)$ & $26.6(5.9)$ \\
\hline \multicolumn{5}{|l|}{ Gender } \\
\hline Male & 30.0 & 32.1 & 28.8 & 29.9 \\
\hline Female & 69.9 & 67.6 & 70.9 & 69.4 \\
\hline Others & 0.4 & 0.3 & 0.3 & 0.8 \\
\hline \multicolumn{5}{|l|}{ Affiliation (Department) ${ }^{* * *}$} \\
\hline Applied Linguistics & 7.9 & 6.4 & 8.3 & 9.0 \\
\hline Applied Psychology & 7.0 & 8.0 & 6.3 & 7.4 \\
\hline Architecture, Design and Civil Engineering & 2.4 & 3.0 & 2.5 & 1.7 \\
\hline Health Professions & 24.5 & 28.4 & 26.4 & 17.6 \\
\hline Life Sciences and Facility Management & 12.4 & 12.1 & 12.7 & 12.4 \\
\hline School of Engineering & 14.7 & 15.7 & 13.0 & 16.7 \\
\hline School of Management and Law & 20.9 & 16.3 & 21.1 & 25.6 \\
\hline Social Work & 9.8 & 10.1 & 9.8 & 9.5 \\
\hline \multicolumn{5}{|l|}{ Bsc./Msc. Level ** } \\
\hline Bachelor students & 87.2 & 84.4 & 86.9 & 90.3 \\
\hline $\begin{array}{l}\text { Master students } \\
\text { Study mode }\end{array}$ & 12.8 & 15.6 & 13.1 & 9.5 \\
\hline Part-time studies & 34.1 & 35.7 & 33.0 & 35.1 \\
\hline Full-time studies & 65.4 & 64.3 & 67.0 & 64.9 \\
\hline \multicolumn{5}{|l|}{ Nationality $(n=2017)$} \\
\hline Swiss & 73.8 & 76.5 & 72.7 & 72.8 \\
\hline Swiss dual citizenship & 17.9 & 15.0 & 19.0 & 19.0 \\
\hline Foreign nationality & 8.3 & 8.5 & 8.3 & 8.2 \\
\hline Subjective Parental Social Status at age $162^{* * *}$ & $5.64(1.64)$ & $5.74(1.65)$ & $5.73(1.56)$ & $5.37(1.78)$ \\
\hline
\end{tabular}

${ }^{1}$ Latent class $1=$ low; $2=$ moderate, $3=$ high impact on wellbeing and daily life, based on latent class analysis;

2 measured by McArthur Scale [25]. $p$-value ${ }^{* * *}<0.001, * *<0.01$.

Table 2 shows the results of the GAD-7 scale. Of the 2429 university students, 2223 students filled out the GAD-7. Most students indicated minimal (38.6\%) and mild symptoms of anxiety (38.6\%), while a about a quarter fell into the severity categories of moderate (10-14) and severe anxiety (15-20) [28].

Table 2. Anxiety sum score and severity levels, unadjusted and adjusted proportions, by latent class $(n=2179)$.

\begin{tabular}{|c|c|c|c|c|c|c|c|}
\hline & $\begin{array}{c}\text { Total } \\
(n=2223)\end{array}$ & \multicolumn{2}{|c|}{ Latent Class $1^{1}(n=615)$} & \multicolumn{2}{|c|}{ Class $2^{1}(n=1004)$} & \multicolumn{2}{|c|}{ Class $3^{1}(n=604)$} \\
\hline GAD-7 sum score ${ }^{2} \mathrm{M}(\mathrm{SD})$ & $6.5(4.4)$ & \multicolumn{2}{|c|}{$3.6(3.1)$} & \multicolumn{2}{|c|}{$6.0(3.5)$} & \multicolumn{2}{|c|}{$10.3(4.5)$} \\
\hline GAD-7 categories (in \%) & & unadj. & adj. $(95 \% \mathrm{CI})^{3}$ & unadj. & adj. $(95 \% \mathrm{CI})^{3}$ & unadj. & adj. $(95 \% \mathrm{CI})^{3}$ \\
\hline Minimal (0-4) & 38.6 & 69.1 & & 38.4 & & 7.8 & \\
\hline Mild (5-9) & 38.6 & 26.5 & & 45.9 & & 38.9 & \\
\hline Moderate (10-14) & 16.4 & 3.1 & & 13.8 & & 34.1 & \\
\hline Severe (15-21) & 6.4 & 1.3 & $1.3(0.4-2.2)$ & 1.8 & $1.7(0.9-2.5)$ & 19.2 & $18.1(14.6-21.5)$ \\
\hline Moderate to severe $(>10)$ & & 4.4 & $4.5(2.8-6.2)$ & 15.6 & $15.5(13.1-17.9)$ & 53.3 & $51.4(47.0-55.9)$ \\
\hline
\end{tabular}

${ }^{1}$ Latent class 1 = low; 2 = moderate, 3 = high impact on wellbeing and daily life, based on latent class analysis;

${ }^{2}$ GAD-7: General anxiety disorder scale; ${ }^{3}$ adjusted for age, sex, social status and affiliation.

\subsection{Latent Class Analysis: Wellbeing and Perception of Everyday Life during Lockdown}

Latent class marginal probabilities for classes 1, 2, and 3 were 0.285 (95\% CI: $0.255-0.318$ ), 0.441 (95\% CI: 0.403-0.479), and 0.274 (95\% CI: 0.240-0.311).

The three latent classes represent clearly distinct profiles (Figure 1). Class 1 comprises students who were generally feeling good or very good, are better able to cope with the challenges induced by self-study, are less worried about their semester degree, perceive less changes in the intensity of conflict, do not feel lonely or locked up, and are better able to enjoy time with their family or partner. Moreover, roughly $30 \%$ of the students in class 1 agreed that the lockdown did not have an impact on their daily lives. 

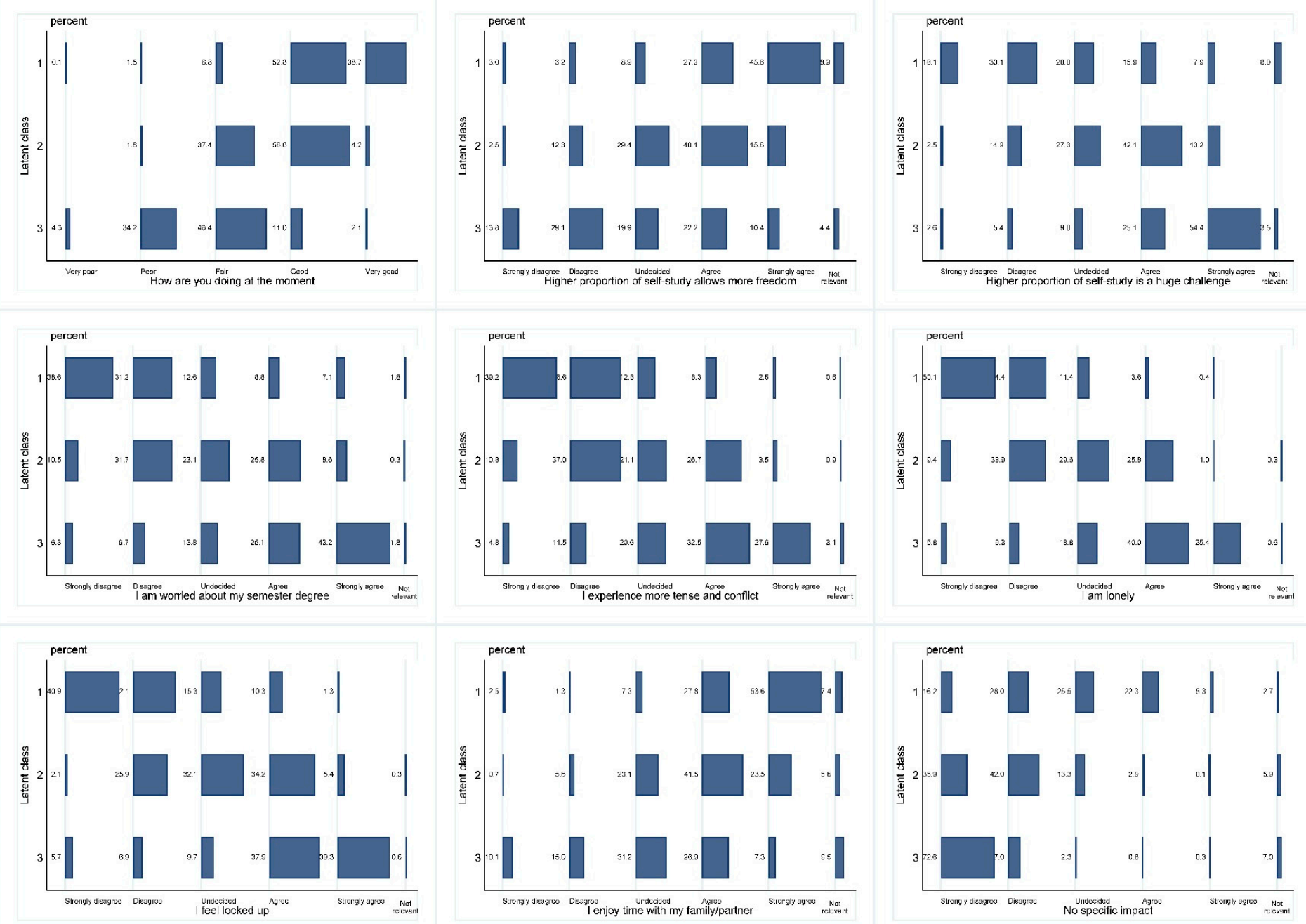

Figure 1. Latent class patterns. Legend: $N=2^{\prime} 429$; Latent class $1=$ low; $2=$ moderate, $3=$ high impact on wellbeing and daily life, based on latent class analysis. 
Class 3 comprises students who generally indicate lower degrees of wellbeing, perceive self-study more challenging, are more worried about their semester degree, experience more tense conflicts, feel more lonely and locked up, are more ambivalent about whether they enjoyed time with their family or partner, and only $8.1 \%$ of the students in class 3 indicated that the lockdown did not have an impact on their everyday life. In many respects, class 2 is more similar to class 1 ; however, students are more often undecided, with large proportions of students in the adjacent categories (disagree or agree).

\subsection{Anxiety}

Students' wellbeing and perceptions of everyday life were associated with anxiety in both OLS models. Compared with students belonging to class 1, students in classes 2 and 3 had substantially higher anxiety scores (Figure 2).
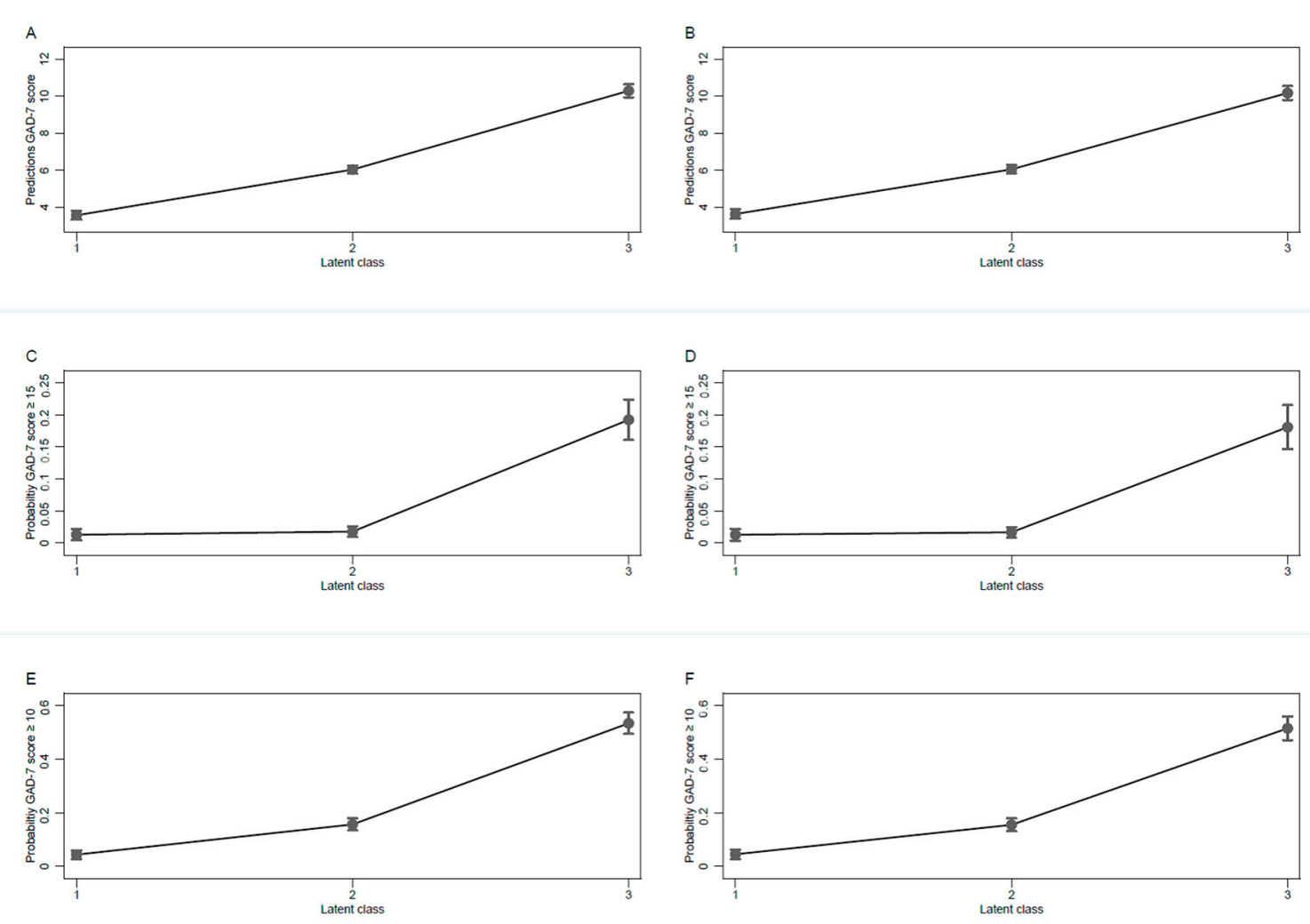

Figure 2. GAD-7 Predicted Marginals. Legend: $N=2$ '223; Latent class $1=$ low; $2=$ moderate, $3=$ strong impact on wellbeing and daily life, based on latent class analysis; GAD 7: General anxiety disorder scale; unadjusted estimates (prediction and probability): A, C, E, estimates adjusted for age, sex, social status and affiliation: B, D, F. A and B estimated from OLS regression models with robust standard errors. C, D, E, and F estimated from logistic regressions with robust standard errors.

Unadjusted and adjusted effects of class membership were of similar magnitude. In the adjusted OLS model, students anxiety score was 2.4 points (95\% CI 2.1-2.8; $p=0.000$ ) higher in class 2 and 6.5 points higher $(95 \% \mathrm{CI} 6.1-7.0 ; p=0.000)$ in class 3 as compared to students in class 1 and the respective predicted anxiety scores, with covariates at their mean value, were 3.6 for class 1 ( $95 \%$ CI: 3.4-3.9; $p=0.000$ ), 6.1 for class 2 (95\% CI 5.8-6.3; $p=0.000$ ), and 10.2 for class 3 (95\% CI: 9.8-10.6; $p=0.000)$ (Table 2).

Regression analyses (Table 3) show that men, compared to women, had somewhat lower anxiety scores $(-1.3 ; 95 \%$ CI: $-1.8-0.9 ; p=0.000)$. Furthermore, anxiety scores differed slightly between faculties. Age, parents' social status, and nationality were not associated with anxiety. 
Table 3. Association between latent classes and General Anxiety Disorder scale (GAD-7).

\begin{tabular}{|c|c|c|c|c|c|c|}
\hline \multirow[b]{3}{*}{ Variable } & \multirow{2}{*}{\multicolumn{2}{|c|}{$\begin{array}{c}\text { Linear Regression Model } \\
\text { GAD-7 Score }{ }^{2} \\
(n=1983)\end{array}$}} & \multicolumn{4}{|c|}{ Logistic Regression Model } \\
\hline & & & \multicolumn{2}{|c|}{ 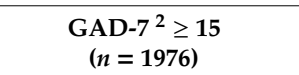 } & \multicolumn{2}{|c|}{$\begin{array}{c}{\text { GAD }-7^{2} \geq 10}^{(n=1983)}\end{array}$} \\
\hline & $b$ & $95 \% \mathrm{CI}$ & OR & $95 \% \mathrm{CI}$ & OR & $95 \% \mathrm{CI}$ \\
\hline \multicolumn{7}{|l|}{ Latent class $(\text { ref }=1)^{1}$} \\
\hline Class $2^{1}$ & $2.41^{* * *}$ & $2.07-2.75$ & 1.29 & $0.55-3.04$ & $3.88^{* * *}$ & $2.51-5.99$ \\
\hline Class $3^{1}$ & $6.53 * * *$ & $6.07-7.00$ & $16.69^{* * *}$ & $7.85-35.48$ & $22.43^{* * *}$ & $14.53-34.63$ \\
\hline \multicolumn{7}{|l|}{ Gender (ref = female) } \\
\hline Male & $-1.34^{* * *}$ & $-1.75-(-0.93)$ & 0.52 & $0.31-0.87$ & $0.54^{* * *}$ & $0.39-0.74$ \\
\hline Other & -1.45 & $-3.80-0.90$ & 1.00 & & 0.28 & $0.02-3.15$ \\
\hline Age (years) & 0.02 & $-0.01-0.05$ & 1.02 & $0.98-1.06$ & $1.02 *$ & $1.00-1.04$ \\
\hline Parent's social status ${ }^{3}$ & -0.10 & $-0.21-0.00$ & 1.07 & $0.94-1.21$ & 0.91 * & $0.85-0.99$ \\
\hline \multicolumn{7}{|l|}{ Nationality (ref = Swiss) } \\
\hline Swiss dual nationality & -0.13 & $-0.55-0.30$ & 1.15 & $0.70-1.91$ & 0.81 & $0.59-1.13$ \\
\hline \multicolumn{7}{|c|}{ Faculty (ref = health professions) } \\
\hline Applied Linguistics & $1.26^{* * *}$ & $0.63-1.90$ & $2.36^{*}$ & $1.14-4.86$ & $1.68 *$ & $1.06-2.65$ \\
\hline Applied Psychology & 0.31 & $-0.39-1.00$ & 1.41 & $0.57-3.48$ & 1.00 & $0.57-1.75$ \\
\hline $\begin{array}{c}\text { Architecture, Design and Civil } \\
\text { Engineering }\end{array}$ & 0.12 & $-0.70-0.95$ & 1.89 & $0.44-8.18$ & 0.86 & $0.34-2.19$ \\
\hline Life Sciences and Facility Management & $1.26^{* * *}$ & $0.71-1.81$ & $2.42 *$ & $1.20-4.88$ & $1.79^{* *}$ & $1.18-2.73$ \\
\hline School of Engineering & 0.44 & $-0.16-1.05$ & 1.47 & $0.66-3.29$ & 1.50 & $0.94-2.40$ \\
\hline School of Management and Law & $0.76^{* *}$ & $0.25-1.28$ & 1.76 & $0.93-3.34$ & $1.56^{*}$ & $1.07-2.27$ \\
\hline Social Work & 0.55 & $-0.09-1.20$ & 1.69 & $0.78-3.70$ & 1.18 & $0.73-1.89$ \\
\hline Constant & $3.45^{* * *}$ & $3.08-3.83$ & $0.01^{* * *}$ & $0.00-0.02$ & $0.04^{* * *}$ & $0.03-00.7$ \\
\hline
\end{tabular}

${ }^{* * *} p<0.001,{ }^{* *} p<0.01,{ }^{*} p<0.05 .{ }^{1}$ Latent class $1=$ low; $2=$ moderate, $3=$ high effect on wellbeing and daily life, based on latent class analysis; ${ }^{2}$ GAD-7: General anxiety disorder scale; ${ }^{3}$ defined by Subjective social status of parents [25] (SSS), Model $n<$ GAD-7 data $/ n=2^{\prime} 223$ ) sample due to missing covariates.

\subsubsection{Severe Anxiety}

Adjusting for gender, age, social class and affiliation had no substantial effect on the probability of belonging to the group with severe anxiety (Tables 2 and 3). In the adjusted logistic regression model, students in class 3 had substantially higher odds of severe anxiety levels (OR $=16.7 ; 95 \%$ CI: 7.8-35.5; $p=0.000$ ) as compared to students in class 1 . However, the odds of severe anxiety did not significantly differ between class 1 and class 2 students (OR $=1.3 ; 95 \%$ CI: $0.6-3.0 ; p=0.554)$. Men as compared to women had substantially smaller odds of reporting severe anxiety (OR $=0.5 ; 95 \% \mathrm{CI}$ : $0.3-0.9 ; p=0.013$ ), while foreign nationals as compared to Swiss nationals had higher odds (OR $=2.3 ; 95 \%$ CI: 1.2-4.3; $p=0.012)$. Similarly, students of applied linguistics (OR $=2.4 ; 95 \%$ CI: $1.1-4.9 ; p=0.020)$ and life sciences and facility management $(2.4 ; 95 \%$ CI: $1.2-4.9 ; p=0.013)$ had higher odds as compared to students of health professions. No statistically significant differences were found between the latter and students of the remaining faculties, nor for age and parents' social status.

\subsubsection{Moderate to Severe Anxiety}

Again, adjustment yielded little change to the results. The adjusted analyses resulted in more than half of the latent class 3 students (53.3\%) reporting moderate to severe anxiety as compared to $4 \%$ in class 1 or $16 \%$ in class 2 (Table 2).

In the adjusted logistic regression model (Table 3), students in classes 2 and 3 had substantially higher odds of moderate to severe anxiety levels ( $\mathrm{OR}=3.9 ; 95 \%$ CI: $2.5-6.0 ; p=0.000)$ and $(\mathrm{OR}=22.4$; 95\% CI: $14.5-34.6 ; p=0.000$ ) as compared to students who were little affected by the lockdown (class 1 ). Men as compared to women had smaller odds of belonging to the moderate to severe anxiety level group (OR $=0.5 ; 95 \% \mathrm{CI}: 0.4-0.7 ; p=0.000)$, as did students with higher social status parents $(\mathrm{OR}=0.91$; 95\% CI: $0.85-0.99 ; p=0.026)$ while older students (OR $=1.02 ; 95 \%$ CI: $1.00-1.04 ; p=0.044)$ had a slightly higher odds. Students of applied linguistics ( $\mathrm{OR}=1.7 ; 95 \% \mathrm{CI}: 1.1-2.7 ; p=0.027)$, life sciences and facility management $(1.8 ; 95 \% \mathrm{CI}: 1.2-2.7 ; p=0.006)$, and management and law (OR $=1.6 ; 95 \% \mathrm{CI}$ : $1.1-2.3 ; p=0.020$ ) had higher odds of moderate to high anxiety levels as compared to students of health professions. 


\section{Discussion}

In this cross-sectional survey, capturing the early phase of the lock-down in Switzerland, a quarter of students showed moderate to severe generalized anxiety. Latent class analyses identified three distinct groups of students, who differ significantly in the impact the COVID-19 pandemic had on their well-being and daily lives. In fact, the high overall prevalence of severe anxiety is driven by students perceiving strong impact by containment measures. Students who felt strongly affected by the measures not only yielded a more than 20-fold adjusted odds of severe anxiety but also had 10- to 14-fold higher within group prevalence of severe anxiety.

The latent class analysis supported the assumption that the subjective perception of the impact differs across student populations. Three classes proved to capture underlying clusters best, resulting in classes of little, moderate, and strong perceived effect of the COVID-19 pandemic on wellbeing and everyday life. The latent classes differentiate those students who appreciate the higher freedom that comes with self-study from those who perceive self-study as a "huge challenge" and are worried about their degrees. The previous literature indicates that abrupt changes and disruption of academic routine can cause considerable distress [9]. Next to university life, daily life was impacted both positively and negatively with increased stress at home, but also enjoying time with one's family. The feeling of loneliness and being locked up was also mentioned far more often by students of the latent class 3 .

The most widely applied measure of anxiety used both in clinical practice and research for screening, diagnosis, and assessment of the severity of anxiety disorders is GAD-7 [29]. The overall mean anxiety score found in our baseline survey was 6.5 and lies above the mean anxiety score in most of the more recent students' health studies. Anwer et al. report a GAD-7 score of 5.3 in a Saudi Arabian college and university sample [30], and Al-Rabiaah a GAD-7 score of 2.7 (SD 3.1) in Saudi Arabian medical students [22]. Lu et al., in a Chinese study, found a mean GAD-7 score of 4.8 (SD 3.8) [31].

Our analyses indicate that COVID-19-specific factors are clearly related to anxiety in students and the prevalence of anxiety. Half of the latent class 3, i.e., students who perceived a strong effect on well-being and everyday life, scored above 10, the cut-off for moderate anxiety, while students, moderately (latent class 2) or little affected (latent class 1 ) only 16\% and $4.5 \%$, respectively, showed corresponding scores. Additional factors associated with high anxiety scores were female gender, higher age, lower perceived parental social status, and faculty affiliation. Most studies identify a higher reporting of anxiety by females as compared to males, and also report an earlier manifestation, higher comorbidity, and a worse outcome [32], as well as increasing prevalence with age [12,13]. In our study, however, adjusting for gender did not change the overall probability of experiencing moderate-severe or severe anxiety levels, nor was gender a significant factor in the logistic regression models on anxiety levels.

Differences in reported anxiety by affiliation have been reported but are less consistent in the literature. In our data, students from the department of health professions showed significantly less anxiety compared to students of management and law, life sciences or linguistics. Health profession students were also significantly less prevalent in latent class 3 as compared to other faculties. Most likely, professional knowledge and experience regarding infection risk and hygiene measures play a role. A pre-COVID university study found differences by faculties, with lowest anxiety in health professions and engineering students [33], while a global study in medical students observed higher general anxiety prevalence in medical students compared to same-age peers [34].

Thus far, a paucity of data in this specific age group collected during the pandemic exist. The study by Elmer et al. in a about 200 students supports our hypothesis of an adverse impact of COVID-19 on anxiety levels, but anxiety was not their main outcome, and partially differs with respect to "concern". The authors found a high prevalence of concern for the participants' own and family members' health, while in our study sample, students reported little concern for their own health, but a third and a quarter reported big concern for grandparents and parents, respectively. Three Chinese studies investigated mental health in college students. Cao et al. report a prevalence of $0.9 \%$ severe, $2.7 \%$ moderate, and $21.3 \%$ mild anxiety in 7143 medical college students [20], very similar prevalence was found 
by Chang et al., with $0.7 \%, 2.71 \%$, and $23.19 \%$, respectively [35] - only an abstract paper in Chinese. The third conducted a longitudinal survey in 66 students and found that the COVID-19 death count had an indirect effect on negative emotions, anxiety and stress mediated through sleep quality [36]. Cultural differences in reporting emotions, anxiety and the regional discourse on COVID-19 and death toll most likely play a role in the magnitude of anxiety found in the different studies. Overall, COVID-19 studies in students are in line with our findings. Further studies on mental health in similar age groups that did not assess anxiety levels, point to the same direction of a negative impact of COVID-19 on other mental health outcomes [23,37]. The body of evidence, albeit still small, indicates the need to enhance mental health services in universities when such acute stressors occur. Universities can offer access to low-threshold support and therapy and thus reduce short- and long-term impact of crises such as pandemics.

As for associated factors Cao et al. report that living alone, coming from a rural area, financial insecurity of family was associated significantly with higher anxiety but not gender or age [20]. An Italian survey on psychological distress in the general population also yields an increased risk for anxiety when living alone and confirms our result on female gender [38]. While we investigated the personal impact on well-being and daily life as well as health concern, other studies asked students if a relative or acquaintance was infected with COVID-19 [20] or was subjected to quarantine [38]. Both found a positive association with these factors and the level of anxiety, underlining that personal experience during the COVID-19 pandemic plays an important role with regard to the COVID-19 impact on mental health.

A limitation of our study is that we cannot infer a causal association between the perceived impact of the public health measures and reported anxiety. However, we do find higher levels of anxiety than pre-COVID-19 studies did. Another limitation is the non-random sampling method (open cohort design) method and the participation rate of $20 \%$ that may have led to some selection bias. However, we find the expected associations with known explanatory characteristics $[20,33,39]$ and students were not informed on the health topics to be investigated. Further, by introducing latent classes, we corroborate not only the hypothesis of a differential perception of the pandemic, but also limit selection bias affecting the observed association between the perception of COVID-19 measures and anxiety levels.

\section{Conclusions}

The data indicate that some students deal better with the dramatic changes they experienced, such as students in health professions, younger and more affluent students. Others fare less well, and with respect to future measures public health and educational institutions should address their needs. The pandemic may reverberate in higher education much longer after the outbreak has been finally controlled and a one-size-fits-all response will not suffice; thus, the authors suggest a close monitoring of health and academic outcomes of university students, and corresponding actions if needed.

Supplementary Materials: The following are available online at http://www.mdpi.com/1660-4601/17/20/7433/s1, Table S1: Overview of topics and instruments HES-C Questionnaire.

Author Contributions: All authors were involved in the interpretation of the data and drafting of the manuscript. J.D.: Conceptualization, methodology, data curation, writing-original draft preparation, supervision, project administration. A.Z.: Conceptualization, formal analysis, data curation, review and editing. N.S.: Data curation, software (programming of questionnaire), review and editing. A.v.W.: Data curation, review and editing. M.H.: Conceptualization, methodology, review and editing. T.V.: Conceptualization, data curation, methodology, formal analysis, review and editing. All authors have read and agreed to the published version of the manuscript.

Funding: This research received no external funding.

Acknowledgments: We thank the ZHAW students for their participation and interest in our study.

Conflicts of Interest: The authors declare no conflict of interest. 


\section{References}

1. Salvatore, R.; Nikki, K.; Jesús, F.B.-M.; David, K. As COVID-19 cases, deaths and fatality rates surge in Italy, underlying causes require investigation. J. Infect. Dev. Ctries. 2020, 14. [CrossRef]

2. Wang, J.; Wang, J.-X.; Yang, G.-S. The Psychological Impact of COVID-19 on Chinese Individuals. Yonsei Med. J. 2020, 61, 438-440. [CrossRef] [PubMed]

3. Brooks, S.K.; Webster, R.K.; Smith, L.E.; Woodland, L.; Wessely, S.; Greenberg, N.; Rubin, G.J. The psychological impact of quarantine and how to reduce it: Rapid review of the evidence. Lancet 2020,395, 912-920. [CrossRef] [PubMed]

4. UNESCO. COVID-19 Educational Disruption and Response; UNESCO: Paris, France, 2020.

5. Holmes, E.A.; O'Connor, R.C.; Perry, V.H.; Tracey, I.; Wessely, S.; Arseneault, L.; Ballard, C.; Christensen, H.; Cohen Silver, R.; Everall, I.; et al. Multidisciplinary research priorities for the COVID-19 pandemic: A call for action for mental health science. Lancet Psychiatry 2020, 7, 547-560. [CrossRef] [PubMed]

6. Liu, J.J.; Bao, Y.; Huang, X.; Shi, J.; Lu, L. Mental health considerations for children quarantined because of COVID-19. Lancet Child Adolesc. Health 2020. [CrossRef]

7. Otu, A.; Charles, C.H.; Yaya, S. Mental health and psychosocial well-being during the COVID-19 pandemic: The invisible elephant in the room. Int. J. Ment. Health Syst. 2020, 14, 38. [CrossRef]

8. Vieta, E.; Pérez, V.; Arango, C. Psychiatry in the aftermath of COVID-19. Rev. Psiquiatr. Salud Ment. 2020. [CrossRef]

9. Zhai, Y.; Du, X. Addressing collegiate mental health amid COVID-19 pandemic. Psychiatry Res. 2020, 288, 113003. [CrossRef]

10. Auerbach, R.P.; Alonso, J.; Axinn, W.G.; Cuijpers, P.; Ebert, D.D.; Green, J.G.; Hwang, I.; Kessler, R.C.; Liu, H.; Mortier, P.; et al. Mental disorders among college students in the World Health Organization World Mental Health Surveys. Psychol. Med. 2016, 46, 2955-2970. [CrossRef]

11. Araújo, F.J.d.O.; de Lima, L.S.A.; Cidade, P.I.M.; Nobre, C.B.; Neto, M.L.R. Impact of Sars-Cov-2 And Its Reverberation In Global Higher Education And Mental Health. Psychiatry Res. 2020, 288, 112977. [CrossRef]

12. Bandelow, B.; Michaelis, S. Epidemiology of anxiety disorders in the 21st century. Dialogues Clin. Neurosci. 2015, 17, 327-335. [PubMed]

13. Kessler, R.C.; Keller, M.B.; Wittchen, H.-U. The Epidemiology of Generalized Anxiety Disorder. Psychiatr. Clin. N. Am. 2001, 24, 19-39. [CrossRef] [PubMed]

14. Wittchen, H.-U.; Jacobi, F. Size and burden of mental disorders in Europe-A critical review and appraisal of 27 studies. Size Burd. Ment. Disord. Eur. 2005, 15, 357-376. [CrossRef]

15. Baxter, A.J.; Scott, K.M.; Vos, T.; Whiteford, H.A. Global prevalence of anxiety disorders: A systematic review and meta-regression. Psychol. Med. 2013, 43, 897-910. [CrossRef]

16. Main, A.; Zhou, Q.; Luecken, L.J. Relations of SARS-related stressors and coping to Chinese college students' psychological adjustment during the 2003 Beijing SARS epidemic. J. Couns Psychol. 2011, 58, 410-423. [CrossRef] [PubMed]

17. Gu, J.; Zhong, Y.; Hao, Y.; Zhou, D.; Tsui, H.; Hao, C.; Gao, Q.; Ling, W.; Lau, J.T.F. Preventive Behaviors and Mental Distress in Response to H1N1 Among University Students in Guangzhou, China. Asia Pac. J. Public Health 2015, 27, NP1867-NP1879. [CrossRef]

18. Goodwin, R.; Gaines, S.O., Jr.; Myers, L.; Neto, F. Initial psychological responses to swine flu. Int. J. Behav. Med. 2011, 18, 88-92. [CrossRef]

19. Usher, K.; Jackson, D.; Durkin, J.; Gyamfi, N.; Bhullar, N. A rapid review of pandemic-related behaviours and psychological outcomes. Int. J. Ment. Health Nurs. 2020. [CrossRef]

20. Cao, W.; Fang, Z.; Hou, G.; Han, M.; Xu, X.; Dong, J.; Zheng, J. The psychological impact of the COVID-19 epidemic on college students in China. Psychiatry Res. 2020, 287, 112934. [CrossRef]

21. Zhou, S.-J.; Zhang, L.-G.; Wang, L.-L.; Guo, Z.-C.; Wang, J.-Q.; Chen, J.-C.; Liu, M.; Chen, X.; Chen, J.-X. Prevalence and socio-demographic correlates of psychological health problems in Chinese adolescents during the outbreak of COVID-19. Eur. Child Adolesc. Psychiatry 2020, 29, 749-758. [CrossRef]

22. Al-Rabiaah, A.; Temsah, M.-H.; Al-Eyadhy, A.A.; Hasan, G.M.; Al-Zamil, F.; Al-Subaie, S.; Alsohime, F.; Jamal, A.; Alhaboob, A.; Al-Saadi, B.; et al. Middle East Respiratory Syndrome-Corona Virus (MERS-CoV) associated stress among medical students at a university teaching hospital in Saudi Arabia. J. Infect. Public Health 2020, 13, 687-691. [CrossRef] [PubMed] 
23. Shanahan, L.; Steinhoff, A.; Bechtiger, L.; Murray, A.L.; Nivette, A.; Hepp, U.; Ribeaud, D.; Eisner, M. Emotional Distress in Young Adults During the COVID-19 Pandemic: Evidence of Risk and Resilience From a Longitudinal Cohort Study. Psychol. Med. 2020, 1-32. [CrossRef]

24. Sotomo. Corona-Krise: Monitoring der Bevölkerung 24/03/20, 2020. Available online: https://sotomo.ch/site/ corona-krise-monitoring-der-bevoelkerung/ (accessed on 12 October 2020).

25. Hoebel, J.; Müters, S.; Kuntz, B.; Lange, C.; Lampert, T. Messung des subjektiven sozialen Status in der Gesundheitsforschung mit einer deutschen Version der MacArthur Scale. Bundesgesundh. Gesundh. Gesundh. 2015, 58, 749-757. [CrossRef]

26. Vermunt, J.K.; Magidson, J. Latent class analysis. In The Sage Encyclopedia of Social Sciences Research Methods; Sage: Thousand Oakes, CA, USA, 2004; pp. 549-553.

27. Galindo Garre, F.; Vermunt, J.K. Avoiding Boundary Estimates in Latent Class Analysis by Bayesian Posterior Mode Estimation. Behaviormetrika 2006, 33, 43-59. [CrossRef]

28. Spitzer, R.L.; Kroenke, K.; Williams, J.B.W.; Löwe, B. A Brief Measure for Assessing Generalized Anxiety Disorder: The GAD-7. Arch. Intern. Med. 2006, 166, 1092. [CrossRef]

29. Moreno, E.; Muñoz-Navarro, R.; Medrano, L.A.; González-Blanch, C.; Ruiz-Rodríguez, P.; Limonero, J.T.; Moretti, L.S.; Cano-Vindel, A.; Moriana, J.A. Factorial invariance of a computerized version of the GAD-7 across various demographic groups and over time in primary care patients. J. Affect. Disord. 2019, 252, 114-121. [CrossRef] [PubMed]

30. Anwer, S.; Alghadir, A.; Manzar, M.D.; Noohu, M.M.; Salahuddin, M.; Li, H. Psychometric Analysis of The Sleep Hygiene Index And Correlation With Stress And Anxiety Among Saudi University Students. Nat. Sci. Sleep 2019, 11, 325-332. [CrossRef] [PubMed]

31. Lu, W.; Bian, Q.; Song, Y.; Ren, J.; Xu, X.; Zhao, M. Prevalence and related risk factors of anxiety and depression among Chinese college freshmen. J. Huazhong Univ. Sci. Technolog. Med. Sci. 2015, 35, 815-822. [CrossRef] [PubMed]

32. Vesga-López, O.; Schneier, F.R.; Wang, S.; Heimberg, R.G.; Liu, S.-M.; Hasin, D.S.; Blanco, C. Gender differences in generalized anxiety disorder: Results from the National Epidemiologic Survey on Alcohol and Related Conditions (NESARC). J. Clin. Psychiatry 2008, 69, 1606-1616. [CrossRef] [PubMed]

33. Grützmacher, J.; Gusy, B.; Lesener, T.; Sudheimer, S.; Willige, J. Gesundheit Studierender in Deutschland 2017. 2018. Available online: https://www.ewi-psy.fu-berlin.de/einrichtungen/arbeitsbereiche/ppg/bwb2017/_inhaltselemente/faktenblaetter/Gesamtbericht-Gesundheit-Studierender-in-Deutschland-2017.pdf (accessed on 12 October 2020).

34. Quek, T.T.-C.; Tam, W.W.-S.; Tran, B.X.; Zhang, M.; Zhang, Z.; Ho, C.S.-H.; Ho, R.C.-M. The Global Prevalence of Anxiety among Medical Students: A Meta-Analysis. Int. J. Environ. Res. Public Health 2019, 16, 2735. [CrossRef]

35. Chang, J.; Yuan, Y.; Wang, D. Mental health status and its influencing factors among college students during the epidemic of COVID-19. Nan Fang Yi Ke Da Xue Xue Bao 2020, 40, 171-176. [CrossRef]

36. Zhang, Y.; Zhang, H.; Ma, X.; Di, Q. Mental Health Problems during the COVID-19 Pandemics and the Mitigation Effects of Exercise: A Longitudinal Study of College Students in China. Int. J. Environ. Res. Public Health 2020, 17, 3722. [CrossRef]

37. Li, Y.; Wang, Y.; Jiang, J.; Valdimarsdóttir, U.A.; Fall, K.; Fang, F.; Song, H.; Lu, D.; Zhang, W. Psychological distress among health professional students during the COVID-19 outbreak. Psychol. Med. 2020, 1-3. [CrossRef] [PubMed]

38. Mazza, C.; Ricci, E.; Biondi, S.; Colasanti, M.; Ferracuti, S.; Napoli, C.; Roma, P. A Nationwide Survey of Psychological Distress among Italian People during the COVID-19 Pandemic: Immediate Psychological Responses and Associated Factors. Int. J. Environ. Res. Public Health 2020, 17, 3165. [CrossRef] [PubMed]

39. Lei, L.; Huang, X.; Zhang, S.; Yang, J.; Yang, L.; Xu, M. Comparison of Prevalence and Associated Factors of Anxiety and Depression Among People Affected by versus People Unaffected by Quarantine During the COVID-19 Epidemic in Southwestern China. Med. Sci. Monit. Int. Med. J. Exp. Clin. Res. 2020, 26, e924609-1-e924609-12. [CrossRef] [PubMed]

(C) 2020 by the authors. Licensee MDPI, Basel, Switzerland. This article is an open access article distributed under the terms and conditions of the Creative Commons Attribution (CC BY) license (http://creativecommons.org/licenses/by/4.0/). 